\title{
Thinking that one's life was in danger: perceived life threat in individuals directly or indirectly exposed to terror
}

\author{
Trond Heir, Ines Blix and Charlotte K. Knatten
}

\section{Background}

Perceived life threat is associated with post-traumatic stress disorder (PTSD). Still, it is not known whether perceived threat may be important for PTSD in people indirectly exposed to trauma.

\section{Aims}

To examine the prevalence of perceived life threat and the association with PTSD in individuals directly or indirectly exposed to terror.

\section{Method}

Data are cross-sectional from a survey 10 months after the 2011 Oslo bombing. Perceived life threat was measured by the question: 'How great do you think the danger was that you would die?' scored on a five-point scale. PTSD was measured with the PTSD Checklist (PCL).

\section{Results}

The retrospective belief that one's life was in great or overwhelming danger was reported by $65 \%$ and $22 \%$ of employees who had been present or not present, respectively, at the site of the bomb explosion $(n=1923)$. A high perceived life threat was associated with PTSD among those present (odds ratio $(\mathrm{OR})=5.7,95 \% \mathrm{Cl} 1.9-16.9)$ and not present (OR=5.2. 95\% Cl 3.0-9.0), even after adjusting for objective exposure, demographics and neuroticism.

\section{Conclusions}

Perceived life threat may play a central role in the development and maintenance of PTSD in people directly as well as indirectly exposed to terror. Moderating perceptions of having been in serious danger may be an appropriate approach to the prevention and treatment of PTSD.

\section{Declaration of interest}

None.

\section{Copyright and usage}

(c) The Royal College of Psychiatrists 2016.
The recollection of life threat, i.e. the belief that one's life was in danger, is consistently associated with post-traumatic stress. ${ }^{1,2}$ Perceived threat can be more strongly related to distress than

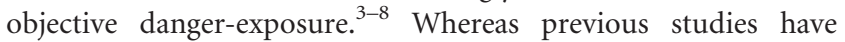
focused on perceived threat as a predictor of post-traumatic stress in people directly exposed to trauma, no studies have provided a similar model for how people not physically present during disasters or terrorist events have developed post-traumatic stress. However, in theories of counterfactual thinking, humans tend to create possible alternatives to past life events. ${ }^{9}$ Given that retrospective appraisals of life threat may be a result of thoughts about what could have happened, it is possible that even people who were not directly exposed to a traumatic episode, in retrospect, may think that their lives were threatened.

Until now, no study has compared perceived threat and posttraumatic stress disorder (PTSD) in individuals directly and indirectly exposed to a potentially traumatic event. Using data from ministerial employees who were present $v$. those not present during the 2011 bombing of the governmental quarters in Oslo, our aim was to examine the prevalence of perceived life threat and its association with PTSD in individuals directly or indirectly exposed to terror. Key questions were whether people would retrospectively evaluate that they had a high risk of dying, even among employees not present at the scene of the attack, and whether levels of perceived life threat would be dependent on physical and psychological proximity to the event. Another question was whether perceived life threat would be associated with PTSD in people directly as well as indirectly exposed to trauma.

\section{Method}

\section{Participants and procedures}

The present study is part of the 'Mental health and work environment factors in the aftermath of the Oslo terrorist attack
22 July 2011' study. ${ }^{10}$ A car bomb blast shattered government buildings, killing 8 people and injuring 209 more. Approximately 4000 ministry employees had their offices in proximity to the epicentre of the explosion. Eligible participants were the 3520 individuals employed in 14 of the 17 Norwegian ministries on 22 July 2011. All 3520 employees were invited to participate in the study, and data were collected between March and June 2012. Prior to data collection, the employees were informed about the purpose and content of the study and given the opportunity to withdraw. The study was approved by the Regional Ethics Committee in Norway.

Of the 3520 invited participants, 1970 (56\%) responded. Of these, 47 (2\%) were excluded from the analysis because of missing outcome variables. Hence, 1923 participants were included in the present study. For the included sample, the mean age was 45.4 years (range 19-70), 1109 (58\%) were women, and 331 (17\%) had leadership responsibilities. There were no significant differences in these demographic characteristics between employees who were present and not present at the governmental district at the time of the bomb explosion (Table 1). There was no significant difference in the proportion of employees who were present during the terrorist attack in the response group $v$. the non-response group, whereas age and the proportion of women were higher among responders. ${ }^{10}$

\section{Measures}

\section{Perceived life threat}

Perceived life threat was measured by the question: 'How great do you think the danger was that you would die??. ${ }^{711}$ The participants responded on a five-point scale: 1 , none; 2 , small; 3 , moderate; 4 , great; 5 , overwhelming. This measure has previously been shown to correlate highly with other items assessing life threat, indicating acceptable scale construct validity. ${ }^{11}$ A score of 4 (great) or 5 
(overwhelming) was considered as high perceived life threat. This choice of cut-off was based on the dose-response relationship between the response categories and post-disaster distress in a previous study. ${ }^{7}$

\section{The PTSD Check List - Specific (PCL-S)}

The PCL is a 17-item self-administered questionnaire that assesses DSM-IV PTSD symptoms. ${ }^{12}$ The participants were asked to indicate on a five-point Likert scale (1, not at all; 5 , extremely) the extent to which they had been bothered by the 17 symptoms in the past month. We used the PCL-S (i.e. symptoms endorsed were linked to the bomb explosion), and we considered an item-score of three or higher to indicate the presence of a particular symptom. ${ }^{13}$ To distinguish between individuals with and without PTSD, the DSM-IV criteria ${ }^{14}$ were applied to the PCL responses. ${ }^{15}$ According to the DSM-IV system, a PTSD diagnosis required one positive score in cluster $\mathrm{B}$ (re-experiencing symptoms), three in cluster C (avoidance symptoms), and two in cluster D (hyperarousal symptoms). The same procedure has performed well for detecting PTSD in the Norwegian population. ${ }^{15}$

\section{Exposure}

The participants were asked about their location at the moment when the bomb exploded, and given five answer choices: (a) in the governmental district downtown; (b) in downtown Oslo, but not in the governmental district; (c) in Oslo, but not downtown; (d) in Norway, but not in Oslo: and (e) abroad. Participants were categorised as being 'present' if they replied (a) they were located in the governmental district; whereas the remaining replies (b-e) were categorised as 'not present. ${ }^{10}$ Furthermore, they were asked three questions whether they had: (a) witnessed people who were dead or dying; (b) who were seriously injured; and (c) whether they were physically injured themselves (yes/no). Questions about indirect exposure were whether the employees

Table 1 Demographic description of ministerial employees

$(n=1923)$, grouped according to whether they were present in the governmental district or not during the 2011 Oslo bombing

\begin{tabular}{|c|c|c|}
\hline & $\begin{array}{l}\text { Present } \\
(n=204)\end{array}$ & $\begin{array}{l}\text { Not present } \\
(n=1719)\end{array}$ \\
\hline Age in years, mean (s.d.) & $44.7(11.8)$ & $45.4(10.8)$ \\
\hline range & 22-70 & 19-69 \\
\hline \multicolumn{3}{|l|}{ Gender, $n$ (\%) } \\
\hline Female & $124(60.8)$ & $985(57.3)$ \\
\hline Male & $80(39.2)$ & $734(42.7)$ \\
\hline Leadership responsibility, ${ }^{a} n(\%)$ & $33(16.7)$ & $298(17.8)$ \\
\hline Neuroticisms, mean (s.d.) & $2.24(0.74)$ & $2.10(0.71)^{\star *}$ \\
\hline range & $1.00-4.50$ & $1.00-5.00$ \\
\hline \multicolumn{3}{|l|}{ Direct exposure, $n(\%)$} \\
\hline Physical injury to self & $52(25.5)$ & - \\
\hline Witnessed people dead or dying & $67(32.8)$ & - \\
\hline Witnessed people seriously injured & $132(64.7)$ & - \\
\hline \multicolumn{3}{|l|}{ Proximity, $n(\%)$} \\
\hline Oslo downtown & - & $168(9.8)$ \\
\hline Oslo periphery & - & $341(19.8)$ \\
\hline Norway outside Oslo & - & $854(49.7)$ \\
\hline Abroad & - & $356(20.7)$ \\
\hline \multicolumn{3}{|l|}{ Indirect exposure, n (\%) } \\
\hline Loss of close colleague & $38(18.6)$ & $220(12.8)^{*}$ \\
\hline Close colleague injured & 108 (52.9) & $808(47.0)$ \\
\hline Damage to one's own office & $134(65.7)$ & $911(53.0)^{\star * *}$ \\
\hline Loss of personal property & $104(51.0)$ & $616(35.8)^{\star * *}$ \\
\hline \multicolumn{3}{|c|}{$\begin{array}{l}{ }^{*} P<0.05,{ }^{*} P<0.01,{ }^{* *} P<0.001 \text {, between group differences. There were no } \\
\text { significant differences in age, gender, or leadership responsibility between the groups. } \\
\text { a. Totals for this variable: present } n=198 \text {; not present } n=1670 \text {. }\end{array}$} \\
\hline
\end{tabular}

had experienced: (a) loss of a close colleague; (b) a close colleague that was injured; (c) damage to one's own office; or (d) loss of personal property (yes/no)

\section{Neuroticism}

The 44-item Big Five Inventory assessing five dimensions of personality traits (extraversion, agreeableness, conscientiousness, neuroticism and openness) was applied. ${ }^{16}$ Neuroticism is generally among the best predictors of post-disaster stress ${ }^{17}$ and was therefore included as a covariate in the present study. The variable consists of eight items that were rated on a five-point Likert scale ( 1 , disagree strongly; 5 , agree strongly). The mean item score was applied, ranging from 1 to 5 .

\section{Demographics}

We assessed characteristics of employees using the following variables: gender, age, and leadership position by asking whether the participant had leadership responsibilities for other employees.

\section{Statistical analyses}

Employees who were present or not present during the traumatic event were compared using the chi-squared or $t$-test for independent samples. We analysed the associations between direct or indirect exposures and the risk of high perceived life threat, and then between perceived life threat and risk of PTSD using logistic regression. We applied the same statistical procedure in the prediction of both perceived life threat and PTSD to achieve comparable results. We used multiple logistic regression analyses to control for covariates that have been shown to predict PTSD, such as direct or indirect exposure, age, gender, leadership responsibility, and neuroticism. ${ }^{10,17}$ Missing data across all variables ranged from $0 \%$ (age, gender, proximity to the bomb explosion, physical injury to self) to $3 \%$ (leadership responsibility). Missing values were dropped through listwise deletion when adding variables to the regression models. Of 1923 responders with data on outcome variables, the number with complete data on all variables was 1833 (95\%) in the regression model with high perceived life threat as outcome and 1848 (96\%) in the model with PTSD as outcome. Participants with missing variables were not different from those with complete data in terms of age, gender, proximity to the bomb explosion, PTSD or perception of life threat ( $t$-tests, chi-squared). All tests were two-tailed and differences were considered significant if $P<0.05$. The statistical analysis was performed with the software package SPSS version 20.0 for Windows.

\section{Results}

High perceived life threat, i.e. the retrospective belief that one's life was in great or overwhelming danger was reported by $22 \%$ (374) of the 1719 employees who had not been present when the bomb exploded and 65\% (133) of the 204 employees who were present in the governmental district $(P<0.001)$. Among those not present, physical proximity to the scene of the attack was associated with high perceived life threat (Table 2). More specifically, the prevalence of perceived life threat increased from $18 \%$ among employees who had been abroad, to $20 \%$ for those who were in Norway, outside Oslo; to $24 \%$ for those who were in the Oslo periphery, and to $33 \%$ for those who were in Oslo downtown $(P<0.001$ linear by linear association). In addition, indirect exposures, such as a close colleague injured, damage to one's own office, and the loss of personal property were independently associated with high levels of perceived life threat (Table 2). 
Among those who were not present, a positive association was also found for neuroticism.

Among employees who had been present, physical injury to self and witnessing people dead or dying were independently associated with a high level of perceived life threat when taking only direct exposure into consideration (Table 2). However, when adjusting for indirect exposure, as well as for demographics and personality, our measures of direct exposure were not significantly related to perceived life threat. On the other hand, female gender and indirect exposure in terms of having a close colleague injured were associated with a high level of perceived life threat.

The symptom criteria for PTSD were met by $4 \%$ (64) of the 1719 employees who had not been present at the time of the incident and 24\% (49) of the 204 employees who had been present $(P<0.001)$. There was a strong association between perceived life threat and the prevalence of PTSD regardless of whether employees had been present during the bomb explosion or not (Table 3). Adjusting for measures of objective exposure, demographics and neuroticism had a low impact on the associations between perceived life threat and PTSD.

\section{Discussion}

\section{Main findings}

The present study examined perceived threat and PTSD in ministerial employees who were present $v$. not present at the scene of the 2011 Oslo bombing. Not surprisingly, the results showed that a higher proportion of employees who were present at the time of the attack experienced a high life threat. Still, a considerable proportion of individuals who had not been present perceived that their life had been in danger. For those who were not present, physical proximity to the scene of terror increased the probability of believing that one's life had been in danger. In addition, psychological proximity, such as having close colleagues that were injured, material damages to one's office and the loss of personal property increased the probability of a retrospective perception of high life threat. Regardless of whether individuals were present at the scene of the attack or not, perceived life threat was associated with PTSD, even when adjusting for other wellknown predictors of PTSD such as gender, age, neuroticism and measures of objective exposure.

\section{Interpretation of our findings}

The present findings demonstrated that even individuals who were not present at the scene of a terrorist attack may, in retrospect, appraise the situation as if their life had been in danger. This is consistent with theories of counterfactual thinking, explaining that humans tend to create possible alternatives to life events that already occurred, and often contrary to what really happened. ${ }^{9}$ Thus, retrospective evaluation of danger may be a result of thoughts of what could have happened. Whether they had been close to the terror scene or not, employees might have been preoccupied by thoughts like 'what if ...' or 'if not ...'

The finding that high perceived life threat was associated with both physical and psychological proximity to the event also corresponds with theories of counterfactual thinking, in which perceived closeness to an alternative outcome makes appraisals of what could have happened more likely. ${ }^{18}$ Thus, our findings can be understood in terms of proximity heuristics and the role of closeness as an indicator of probability. ${ }^{19-21}$ Our findings suggest that neuroticism may affect the tendency to think that one's life was in danger. Rumination and worry often accompany neuroticism, and may include thoughts of adverse outcomes of what could have happened.

Table 2 Associations between direct or indirect exposures to terror and high perceived life threat ${ }^{\mathrm{a}}$ among ministerial employees $(n=1923)$ who were present in the government district or not during the 2011 Oslo bombing: stepwise logistic regression adjusting for other variables

\begin{tabular}{|c|c|c|c|c|}
\hline & \multicolumn{2}{|c|}{ Present $(n=204)$} & \multicolumn{2}{|c|}{ Not present $(n=1719)$} \\
\hline & OR $(95 \% \mathrm{Cl})$ & $P$ & OR $(95 \% \mathrm{Cl})$ & $P$ \\
\hline \multicolumn{5}{|l|}{ Step $1 A$ (direct exposure) } \\
\hline Physical injury to self & $3.25(1.40-7.53)$ & 0.006 & - & \\
\hline Witnessed people dead or dying & $2.52(1.20-5.30)$ & 0.015 & - & \\
\hline Witnessed people seriously injured & $1.56(0.81-3.01)$ & 0.19 & - & \\
\hline \multicolumn{5}{|l|}{ Step $1 B$ (proximity) } \\
\hline Abroad & - & & Ref & \\
\hline Norway & - & & $1.13(0.82-1.55)$ & 0.45 \\
\hline Oslo periphery & - & & $1.42(0.98-2.04)$ & 0.06 \\
\hline Oslo downtown & - & & $2.18(1.43-3.32)$ & $<0.001$ \\
\hline \multicolumn{5}{|c|}{ Step 2 (adding indirect exposure, demographics and personality) } \\
\hline \multicolumn{5}{|c|}{ Direct exposure } \\
\hline Physical injury to self & $1.91(0.73-5.00)$ & 0.19 & - & \\
\hline Witnessed people dead or dying & $1.90(0.80-4.51)$ & 0.15 & - & \\
\hline Witnessed seriously injured & $1.93(0.90-4.11)$ & 0.090 & - & \\
\hline \multicolumn{5}{|l|}{ Proximity } \\
\hline Abroad & - & & Ref & \\
\hline Norway & - & & $1.12(0.80-1.56)$ & 0.52 \\
\hline Oslo periphery & - & & $1.23(0.83-1.82)$ & 0.31 \\
\hline Oslo downtown & - & & $2.43(1.55-3.81)$ & $<0.001$ \\
\hline Loss of close colleague & $0.62(0.23-1.67)$ & 0.34 & $1.39(0.99-1.95)$ & 0.057 \\
\hline Close colleague injured & $2.57(1.10-6.00)$ & 0.029 & $1.62(1.23-2.15)$ & 0.001 \\
\hline Damage to one's own office & $1.10(0.45-2.66)$ & 0.84 & $1.85(1.31-2.62)$ & $<0.001$ \\
\hline Loss of personal property & $1.83(0.72-4.66)$ & 0.20 & $1.61(1.15-2.24)$ & 0.005 \\
\hline Gender (female $v$. male) & $2.24(1.06-4.72)$ & 0.035 & $1.01(0.78-1.30)$ & 0.96 \\
\hline Age (increase of 10 years) & $1.08(0.80-1.45)$ & 0.61 & $1.13(1.01-1.27)$ & 0.036 \\
\hline Leadership (yes v. no) & $2.65(0.97-7.22)$ & 0.057 & $0.90(0.64-1.25)$ & 0.53 \\
\hline Neuroticism & $1.55(0.92-2.62)$ & 0.10 & $1.20(1.01-1.43)$ & 0.037 \\
\hline
\end{tabular}




\begin{tabular}{|c|c|c|c|c|}
\hline & \multicolumn{2}{|c|}{ Present $(n=204)$} & \multicolumn{2}{|c|}{ Not present $(n=1719)$} \\
\hline & OR $(95 \% \mathrm{Cl})$ & $P$ & OR $(95 \% \mathrm{Cl})$ & $P$ \\
\hline \multicolumn{5}{|l|}{ Step 1} \\
\hline High perceived life threat ${ }^{a}$ & $6.53(2.45-17.36)$ & $<0.001$ & $5.36(3.22-8.93)$ & $<0.001$ \\
\hline \multicolumn{5}{|l|}{ Step 2 (Adding direct exposure) } \\
\hline High perceived life threat & $5.87(2.15-16.03)$ & 0.001 & & \\
\hline Physical injury to self & $1.27(0.60-2.67)$ & 0.54 & & \\
\hline Witnessed people dead or dying & $0.93(0.45-1.96)$ & 0.86 & & \\
\hline Witnessed people seriously injured & $1.63(0.72-3.69)$ & 0.24 & & \\
\hline \multicolumn{5}{|c|}{ Step 3 (Adding demographics and personality) } \\
\hline High perceived life threat & $5.65(1.89-16.86)$ & 0.002 & $5.15(2.96-8.96)$ & $<0.001$ \\
\hline Physical injury to self & $1.03(0.44-2.42)$ & 0.95 & & \\
\hline Witnessed people dead or dying & $0.90(0.39-2.09)$ & 0.80 & & \\
\hline Witnessed people seriously injured & $2.16(0.84-5.55)$ & 0.11 & & \\
\hline Gender (female $v$. male) & $2.50(1.04-6.03)$ & 0.041 & $1.19(0.66-2.14)$ & 0.57 \\
\hline Age (increase of 10 years) & $0.89(0.64-1.25)$ & 0.51 & $1.19(0.93-1.53)$ & 0.17 \\
\hline Leadership (yes $v$. no) & $0.63(0.20-1.95)$ & 0.42 & $0.52(0.18-1.51)$ & 0.23 \\
\hline Neuroticism & $2.98(1.73-5.14)$ & $<0.001$ & $3.54(2.50-5.02)$ & $<0.001$ \\
\hline
\end{tabular}

The high levels of perceived life threat suggest an upward estimation of the risk of dying. Although $65 \%$ of the employees who were present at the time of the explosion believed that their life had been in great or overwhelming danger, the true mortality rate for this group was $2 \%$. On the other hand, the prevalence of high life threat was $22 \%$ among employees not present, despite that the mortality rate was $0.2 \%$ for all employees included. In fact, $99.8 \%$ of all the ministerial employees survived the terrorist attack, making odds for survival for a random employee quite high. The discrepancies are in accordance with experimental studies showing that subjective risks of dying are generally severely overestimated. ${ }^{19,21}$ Additionally, the catastrophic potential of a terrorist attack may influence people's probability judgments. ${ }^{22}$

The strong association between perceived life threat and PTSD is in agreement with previous research. ${ }^{1,2,6,23-26}$ The present study extends these findings by demonstrating an equally strong association between perceived life threat and PTSD in individuals who were not directly exposed to trauma. Our findings support the notion that thoughts of what could have been continuously affect people's emotions, ${ }^{27}$ and that ruminations on alterative outcomes can influence processes essential to PTSD development and recovery. ${ }^{28,29}$

\section{Limitations}

The present study has some limitations. First, the cross-sectional design of the present study does not allow conclusions about causality. Future longitudinal studies are needed to explore the directionality of the association between perceived life threat and PTSD. Second, exposure variables were collected 10 months after the event, and only assessed by self-reported measures. Third, the diagnosis of PTSD was determined by a self-reported instrument (PCL-S), and not by clinical diagnosis. However, the Norwegian version of the PCL-S performs nearly as well as the Structural Clinical Interview for DSM-IV (SCID-I) in its ability to detect PTSD in epidemiological research. ${ }^{15}$ Finally, we have not considered fulfilment of the PTSD A criterion, but only taken into account the burden of symptoms.

\section{Implications}

Our findings may have implications for public health strategies and the prevention and treatment of PTSD. Although a higher proportion of those who had been present at the scene of the terror attack reported that their life had been in great or overwhelming danger, the absolute number of employees that reported high life threat was higher among those who were not present. The same was true for PTSD, i.e. the total number of employees that met the symptom criteria of PTSD was higher among employees who had not been present than among those who were present. This may illustrate the outcome of many disasters, as well as stressful events of lesser magnitude. A low risk of severe stress reactions in more peripheral circuits may result in a very high number of affected individuals, as stated by Geoffrey Rose's fundamental axiom in preventive medicine: 'a large number of people exposed to a small risk may generate many more cases than a small number exposed to a high risk. ${ }^{30}$ Hence, a high-risk prevention strategy focusing solely on the individuals who are judged most likely to develop stress reactions may deal with only part of the problem. Our findings illustrate that post-disaster healthcare should be planned for large groups and not only for the group with the highest prevalence of a risk factor or a mental illness. One option might be a low-threshold service for mental health and psychosocial support that is available for anyone who is adversely affected by a disaster event.

A population strategy of prevention is necessary whenever risk is widely diffused through a larger population. ${ }^{31}$ According to general principles in situations where many people are exposed to some risk, ${ }^{30,31}$ a small shift in the distribution of perceived threat may have a large effect on the number of people with PTSD. Thus, moderating perceptions of having been in serious danger may be an appropriate approach to the prevention of PTSD. Attention to the event and its possible adverse effects may cause unintended appraisals and perceptions that people have been exposed to serious danger. In that respect, more research is necessary to determine how various aspects of disasters, such as media coverage, early intervention programmes, and various compensatory mechanisms affect people's perception of having been in serious danger. It has been well demonstrated that recalled threat intensity may increase with time, and that such recall amplification may hinder recovery from post-traumatic stress. ${ }^{11}$ Thus, health professionals, disaster workers and authorities should be aware of possible harmful effects of promoting perceptions of serious danger. 
Moderation of retrospective threat appraisals may be an appropriate approach in cognitive therapy. It is well accepted that thoughts about what could have been can interfere with processes essential to recovery. ${ }^{29}$ Overestimations of the risk of dying suggest that therapeutic approaches that promote objective threat evaluation would be beneficial. An active reconstruction and cognition of the factual course of events may be a useful tool in this process. $^{32}$

Previous studies have not provided an explanation of how people not physically present have developed post-traumatic stress after disasters or terrorist events. ${ }^{33-36}$ Based on the present findings, counterfactual thoughts about serious threats to one's life may be the clue needed to fill in this gap. This underlines the importance of understanding cognitive processes and, more specifically, counterfactual evaluations in the aftermath of trauma. ${ }^{37,38}$ It may well be that the same processes are essential, regardless of physical proximity to a catastrophic event.

Trond Heir, PhD, Norwegian Centre for Violence and Traumatic Stress Studies, Oslo, and Institute of Clinical Medicine, University of Oslo; Ines Blix, PhD, Charlotte K. Knatten, PhD, Norwegian Centre for Violence and Traumatic Stress Studies, Olso, Knatten,
Norway

Correspondence: Trond Heir, Norwegian Centre for Violence and Traumatic Stress Studies, Gullhaugveien 1-3, 0484 Oslo, Norway. Email: trond.heir@ medisin.uio.no

First received 22 May 2015, final revision 21 Oct 2015, accepted 29 oct 2015

\section{Funding}

This work was supported by The Norwegian Directorate of Health

\section{References}

1 King LA, King DW, Bolton EE, Knight JA, Vogt DS. Risk factors for mental, physical, and functional health in Gulf War veterans. J Rehabil Res Dev 2008; 45: 395-407.

2 Mott JM, Graham DP, Teng EJ. Perceived threat during deployment: risk factors and relation to axis I disorders. Psychol Trauma 2012; 4: 587-95.

3 Creamer M, Burgess P, Buckingham W, Pattison P. Posttrauma reactions following a multiple shooting. In International Handbook of Traumatic Stress Syndromes (eds JP Wilson, B Raphael): 201-12. Plenum Press, 1993.

4 King DW, King LA, Gudanowski DM, Vreven DL. Alternative representations of war zone stressors: relationships to posttraumatic stress disorder in male and female Vietnam veterans. J Abnorm Psychol 1995; 104: 184-95.

5 Ozer EJ, Best SR, Lipsey TL, Weiss DS. Predictors of posttraumatic stress disorder and symptoms in adults: a meta-analysis. Psychol Bull 2003; 129 52-73.

6 Vogt DS, Tanner LR. Risk and resilience factors for posttraumatic stress symptomatology in Gulf War I veterans. J Trauma Stress 2007: 20: 27-38.

7 Heir T, weisæth L. Acute disaster exposure and mental health complaints of Norwegian tsunami survivors six months post disaster. Psychiatry 2008; 71 : 266-76.

8 Lazarus RS, Folkman S. Stress, Appraisal, and Coping. Springer, 1984.

9 Epstude K, Roese NJ. The functional theory of counterfactual thinking. Pers Soc Psychol Rev 2008; 12: 168-92.

10 Hansen MB, Nissen A, Heir T. Proximity to terror and post-traumatic stress: a follow-up survey of governmental employees after the 2011 Oslo bombing attack. BMJ Open 2013; 3: e002692.

11 Heir T, Piatigorsky A, Weisæth L. Longitudinal changes in recalled perceived life threat after a natural disaster. Br J Psychiatry 2009; 194: 510-4.

12 Weathers F, Ford J. Psychometric properties of the PTSD Checklist (PCL-C, PCL-S, PCL-M, PCL-PR). In Measurement of Stress, Trauma and Adaptation (eds BH Stamm, MD Lutherville): 250-1. Sidran Press, 1996.
13 National Center for PTSD. Using the PTSD Checklist for DSM-IV (PCL). National Center for PTSD, 2014 (http://www.ptsd.va.gov/professional/pages/ assessments/assessment-pdf/pcl-handout.pdf).

14 American Psychiatric Association. Diagnostic and Statistical Manual of Mental Disorder (4th edn) (DSM-IV). APA, 1994

15 Hem C, Hussain A, Wentzel-Larsen T, Heir T. The Norwegian version of the PTSD Checklist (PCL): construct validity in a community sample of 2004 tsunami survivors. Nord J Psychiatry 2012; 66: 355-9.

16 Rammstedt B, John OP. Measuring personality in one minute or less: a 10-item short version of the Big Five Inventory in English and German. J Res Pers 2007; 41: 203-12.

17 Norris FH, Friedman MJ, Watson PJ, Byrne CM, Diaz E, Kaniasty K. 60,000 disaster victims speak: part I. An empirical review of the empirical literature, 1981-2001. Psychiatry 2002; 65: 207-39.

18 Roese NJ, Olson JM. Counterfactual thinking: the intersection of affect and function. Adv Exp Soc Psychol 1997; 29: 1-59.

19 Teigen $\mathrm{KH}$. The proximity heuristic in judgments of accident probabilities. Br J Psychol 2005; 96: 423-40.

20 Kahneman D, Varey CA. Propensities and counterfactuals: the loser that almost won. J Pers Soc Psychol 1990; 59: 1101-10.

21 Teigen $\mathrm{KH}$. When the unreal is more likely than the real: post hoc probability judgements and counterfactual closeness. Think Reason 1998; 4: $147-77$.

22 Verplanken B. The effect of catastrophe potential on the interpretation of numerical probabilities of the occurrence of hazards. J Appl Soc Psychol 1997; 27: 1453-67.

23 Gil S, Caspi Y. Personality traits, coping style, and perceived threat as predictors of posttraumatic stress disorder after exposure to a terrorist attack: a prospective study. Psychosom Med 2006; 68: 904-9.

24 Holbrook TL, Hoyt DB, Stein MB, Sieber WJ. Perceived threat to life predicts posttraumatic stress disorder after major trauma: risk factors and functional outcome. J Trauma 2001; 51: 287-93.

25 Kolkow TT, Spira JL, Morse JS, Grieger TA. Post-traumatic stress disorder and depression in health care providers returning from deployment to Iraq and Afghanistan. Mil Med 2007; 172: 451-5.

26 Mayou R, Ehlers A, Bryant B. Posttraumatic stress disorder after motor vehicle accidents: 3-year follow-up of a prospective longitudinal study. Behav Res Ther 2002; 40: 665-75.

27 Markman KD, Klein WM, Suhr JA. Handbook of Imagination and Mental Simulation. Psychology Press, 2012.

28 Dunmore E, Clark DM, Ehlers A. A prospective investigation of the role of cognitive factors in persistent posttraumatic stress disorder (PTSD) after physical or sexual assault. Behav Res Ther 2001; 39: 1063-84.

29 Ehlers A, Clark DM. A cognitive model of posttraumatic stress disorder. Behav Res Ther 2000; 38: 319-45.

30 Rose G. The Strategy of Preventive Medicine. Oxford University Press, 1992.

31 Rose G. Sick individuals and sick populations. Int J Epidemiol 2001; 30 427-32.

32 Heir T, Weisæth L. Back to where it happened: self-reported symptom improvement of tsunami survivors who returned to the disaster area. Prehosp Disaster Med 2006; 21: 59-63.

33 Dixon $P$, Rehling G, Shiwach R. Peripheral victims of the Herald of Free Enterprise disaster. Br J Med Psychol 1993; 66: 193-202.

34 Pfefferbaum B, Seale TW, McDonald NB, Brandt EN Jr, Rainwater SM, Maynard BT, et al. Posttraumatic stress two years after the Oklahoma City bombing in youths geographically distant from the explosion. Psychiatry 2000; 63: 358-70.

35 Silver RC, Holman EA, McIntosh DN, Poulin M, Gil-Rivas V. Nationwide longitudinal study of psychological responses to September 11. JAMA 2002; 288: $1235-44$

36 Stein BD, Elliott MN, Jaycox, LH, Collins RL, Berry SH, Klein DJ, et al. A national longitudinal study of the psychological consequences of the September 11 2001 terrorist attacks: reactions, impairment, and help-seeking. Psychiatry 2004; 67: 105-17.

37 Dalgleish T. What might not have been: an investigation of the nature of counterfactual thinking in survivors of trauma. Psychol Med 2004; 34 1215-25.

38 El Leithy S, Brown GP, Robbins I. Counterfactual thinking and posttraumatic stress reactions. J Abnorm Psychol 2006; 115: 629-35. 